\title{
Evaluation of Medical students perception on Personal Drug Selection for improving prospective Medical Education: A situational Analysis from Manipal College of Medical Sciences, Pokhara, Nepal
}

\author{
Banerjee $I^{1,2}$, Saha $A^{3}$, Sathian $B^{4}$, Roy $B^{5}$, Banerjee $I^{6}$ \\ ${ }^{1}$ Assistant Professor, M.D, Dr. D.Y.Patil Medical College, Ebene, Mauritius, ${ }^{2}$ Assistant Professor, M.D, Department \\ of Pharmacology, Manipal College of Medical Sciences, Pokhara, Nepal, ${ }^{3}$ Professor and Head of the Department of \\ Pharmacology, M.D Manipal College of Medical Sciences, Pokhara, Nepal, ${ }^{4}$ Assistant Professor, P.hD, Department \\ of Community Medicine, Manipal College of Medical Sciences, Pokhara, Nepal, ${ }^{5}$ Assistant Professor, Department of \\ Physiology, M.Sc, Manipal College of Medical Sciences, Pokhara, Nepal, ${ }^{6}$ Post Doctorate Trainee, M.Ch Urology, SMS \\ Medical College, M.S, Rajasthan, India
}

*Corresponding Author: Dr Indrajit Banerjee MD Assistant Professor, Department of Pharmacology Dr. D.Y. Patil Medical College, Ebene, Mauritius

Email: indrajit18@gmail.com

\section{ABSTRACT}

Background: Personal (P) drug selection is an important part of the pharmacology teaching and learning session. Most of the textbooks that are commonly followed by the medical schools of Nepal merely tell about the concepts of $\mathrm{P}$ drug selection. $\mathrm{P}$ drug selection lets students to think and make decisions about the drugs prescribed. The main objective of the study was to find the Medical students perspective of P- Drug selection from a medical college of Nepal.

Methods: This cross sectional questionnaires based study was carried out at Manipal College of Medical Sciences, Pokhara, Nepal from July 2008- July 2013. Chi square test and Odds Ratio were used for analytical purpose. Questionnaire validation tests showed that the Alpha Cronbach was 0.72 .

Results: P drug selection is an important part of MBBS curriculum, which was reflected by $74.9 \%$ of the medical students. Most of the students, around $82 \%$ responded that $\mathrm{P}$ drug is for a disease and $85 \%$ students felt that time should be increased for the exercise. Around $90.1 \%$ students felt that $\mathrm{P}$ drug selection gives knowledge of the full chapter and $90.1 \%$ of the students found it difficult to find out the cost of the drugs from different brands.

Conclusion: The overall views of medical students on P drug selection were positive. The teaching and learning activity of P Drug Selection needs improvement in certain areas. In this exercise a student learns the rationale drug usage for a particular disease objectively and in an unbiased manner. With proper amendments in the teaching and learning methodology of $\mathrm{P}$ drug selection students can think and make decisions about the prescription writing, furthermore can reduce the chances of irrational prescribing by the future doctors.

Keywords: P Drug, Rational Medicines, Nepal 


\section{Background}

In Nepal MBBS Curriculum is four and half year course. Pharmacology is taught in the first two years of the course. ${ }^{1}$ Personal (P) drug selection is an important part of the pharmacology teaching and learning session. This exercise is practiced when a medical student enters into the second year of MBBS course at Manipal College of Medical Sciences. The activity of $\mathrm{P}$ drug selection can reduce irrational prescribing which common problem across the world. ${ }^{2}$

Most of the time it is found that student cannot follow the concepts of $\mathrm{P}$ drug. Most of the textbooks that are commonly followed by the medical schools of Nepal merely tell about the concepts of P drug selection. Guide to good prescribing and teachers guide to good prescription gives a good knowledge regarding the concepts of $\mathrm{P}$ dug. ${ }^{3,4}$ The practical exercise of $\mathrm{P}$ Drug selection helps to prescribe medicines based on objective criteria of efficacy, safety, cost, convenience/suitability and unbiased sources of medicine information. At present the P-drug selection is carried out at very few medical schools of Nepal namely MCOMS, KISTMC ${ }^{5}$ and IOM in Nepal. Traditional pharmacology teaching and learning methodology does not train the students to think and make decisions about the prescription writing. ${ }^{6}$ The main objective of the study was to find the Medical students perspective of P- Drug selection from a medical school of Nepal.

\section{Methods}

\section{Study design and the participants:}

This was a cross sectional questionnaires based study which was conducted at Manipal College of Medical Sciences, Pokhara, Nepal.

\section{Data collection:}

The study was carried out between $1^{\text {st }}$ July 2008- $1^{\text {st }}$ July 2013 at Manipal College of Medical Sciences, Pokhara, Nepal. Data was collected when student entered into the second year of the MBBS course and it was collected for five consecutive years. The collected data includes demographic details such as gender (male and female), Nationality (Indian, Srilankan and Nepalese students). Questionnaire validation tests showed that the Alpha Cronbach was 0.72 .

\section{Inclusion criteria:}

All the medical students when entered into the second year of the MBBS course were included in the study from a period of $1^{\text {st }}$ July 2008- $1^{\text {st }}$ July 2013 at Manipal College of Medical Sciences, Pokhara, Nepal.

\section{Response rate:}

Out of 712 students, 605 students filled the questionnaires properly and completely which indicates overall response rate of $84.97 \%$.

\section{Exclusion criteria:}

The questionnaire was rejected based on the incomplete filling of the form and absence of the students from the class.

Sample size calculation: For $95 \%$ confidence interval and significance level $\alpha=5 \%, \mathrm{P}=70 \%, \mathrm{Q}=30 \%$, allowable error $=10 \%$ of $\mathrm{P}$. $\mathrm{P}$ is the proportion or $\%$ of the students found $\mathrm{P}$ drug selection as an important part of MBBS Curriculum [Outcome measure of main variable]. $\mathrm{Q}$ is the complement of $\mathrm{P}$. [Q=100-P].The required sample size was 428 . Prior to the study a pilot study was done in 50 students and it was found that $70 \%$ of the students found $\mathrm{P}$ drug selection as an important part of MBBS Curriculum. We got an adequate sample size of 605 . $^{7}$

\section{Outcome Variable:}

The main outcome variable was whether $\mathrm{P}$ drug selection is an important lesson in MBBS Curriculum (yes/no), P drug is for patient or doctor, time of selection of $\mathrm{P}$ drug is to be increased (yes/no), Difficult to find out which portion of $\mathrm{P}$ drug (efficacy, safety, convenience, cost), P drug selection gives knowledge about the full chapter (yes/ no).

\section{Explanatory variables:}

Factors which were taken into consideration at individual level were gender (male and Nationality (Indian, Srilankan and Nepali) of the medical students.

\section{Ethical committee approval:}

The Research was conducted in accordance to latest version of the Declaration of Helsinki ${ }^{8}$. Prior the study, ethical committee approval was taken from the institutional ethical committee, Manipal Teaching hospital, Pokhara, Nepal.

\section{Data management and statistical analysis:}

The data collected was analyzed using Statistical Package for the Social Sciences (SPSS) for Windows Version 20.0 (SPSS Inc; Chicago, IL, USA). Chi square test was used to observe the relationship between different variables and strength of the relationship with logistic regression. We calculated odds ratios and their 95\% confidence intervals $(95 \% \mathrm{CI}) . \mathrm{p}<0.05$ was considered as statistically significant.

\section{Results}


Out of 605 students, male were $57.9 \%$ and rest were females. As per as Nationality, $46.6 \%$ of the students were Nepalese followed by Srilankan $21.5 \%$ and Indian $31.9 \%$ respectively. About $74.9 \%$ of the medical students felt $\mathrm{P}$ drug selection is an important part of MBBS curriculum. $82 \%$ responded that $\mathrm{P}$ drug is for a disease. Among all students $85 \%$ students felt that time should be increased. $90.1 \%$ students felt that $\mathrm{P}$ drug selection gives knowledge of the full chapter, whereas $90.1 \%$ of the students found it difficult to find out the cost of the drugs from different brands (Table 1).

Table 1: Frequency of Gender and Nationality of the medical students and P Drug Selection

\begin{tabular}{|c|c|c|c|}
\hline & & $n=605$ & Percentages \\
\hline \multirow[t]{2}{*}{ Gender } & Female & 255 & $42.1 \%$ \\
\hline & Male & 350 & $57.9 \%$ \\
\hline \multirow[t]{3}{*}{ Nationality } & Nepalese & 282 & $46.6 \%$ \\
\hline & Srilankan & 130 & $21.5 \%$ \\
\hline & Indian & 193 & $31.9 \%$ \\
\hline \multirow{9}{*}{$\begin{array}{l}\text { P Drug } \\
\text { Selection }\end{array}$} & Important Lesson for & 453 & $74.9 \%$ \\
\hline & MBBS Curriculum & & \\
\hline & Not an Important & 152 & $25.1 \%$ \\
\hline & Lesson for MBBS & & \\
\hline & Curriculum & & \\
\hline & For patient & 109 & $18 \%$ \\
\hline & For Disease & 496 & $82 \%$ \\
\hline & Time to be increased & 514 & $85 \%$ \\
\hline & $\begin{array}{l}\text { Gives knowledge of } \\
\text { the full chapter }\end{array}$ & 545 & $90.1 \%$ \\
\hline \multirow{4}{*}{$\begin{array}{l}\text { Difficult to } \\
\text { calculate }\end{array}$} & Efficacy & 33 & $5.5 \%$ \\
\hline & Safety & 17 & $2.8 \%$ \\
\hline & Convenience & 10 & $1.7 \%$ \\
\hline & Cost & 545 & $90.1 \%$ \\
\hline
\end{tabular}

About $80.6 \%$ of all male and $67.1 \%$ of female students felt $\mathrm{P}$ Drug selection is an important lesson for MBBS Curriculum. Interestingly $82 \%$ of all students responded as P Drug selection is for a disease whereas $18 \%$ thinks that it is for a patient. Most of the student felt that the time given for selection of P Drug is not sufficient and has to be increased $80.4 \%$ of all females and $88.3 \%$ of all male students. P drug selection gives a full knowledge of the chapter was opted by most of the students $90.9 \%$ boys and $89 \%$ of all girls. Most of the student found calculating the cost of drugs from different brands is difficult as compared to find efficacy, safety and convenience (Table 2).

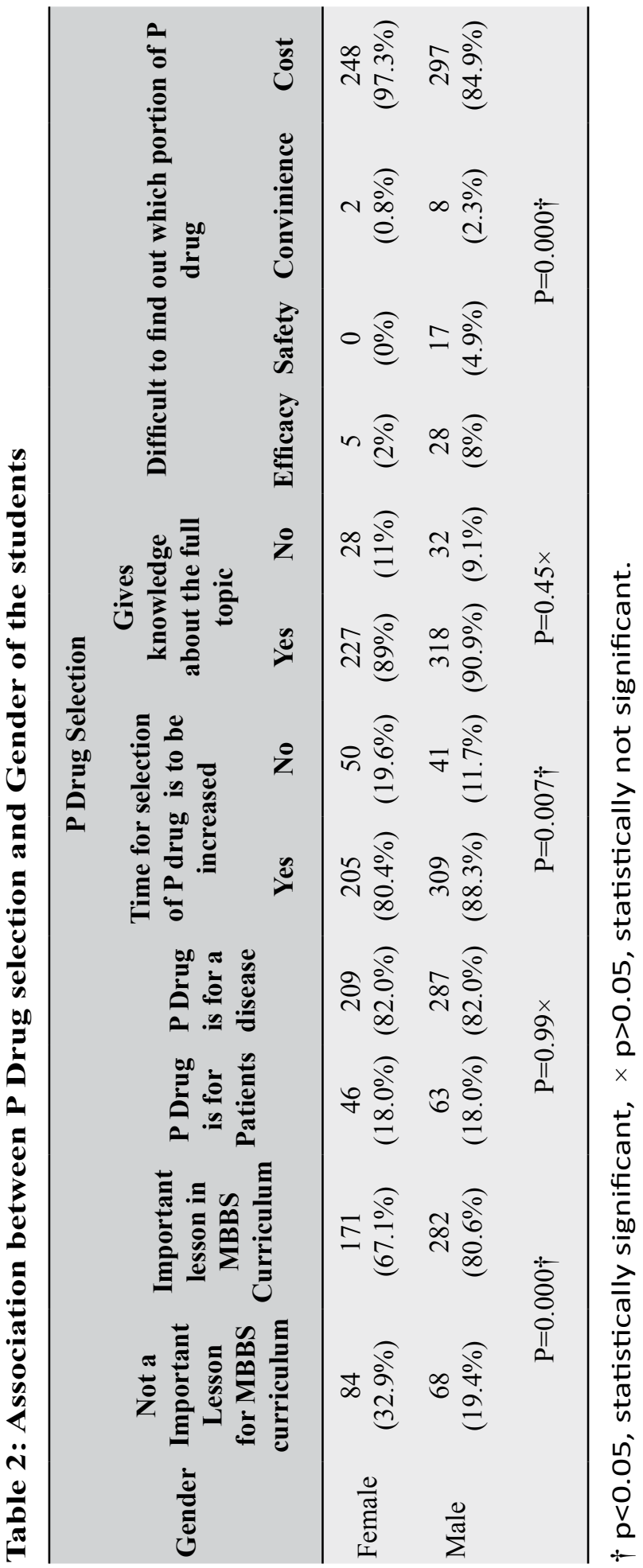

Table 3 revealed that most of the students from different Nationality found P Drug selection as an important lesson. About $27.7 \%$ of Srilankan students thought P Drug is for patient. Whereas $85.5 \%$ of the Nepalese students responded that P Dug is for a disease. $93.3 \%$ of all Nepalese students 
found calculation of costs from different brands was the most difficult portion of P Drug selection (Table 3).

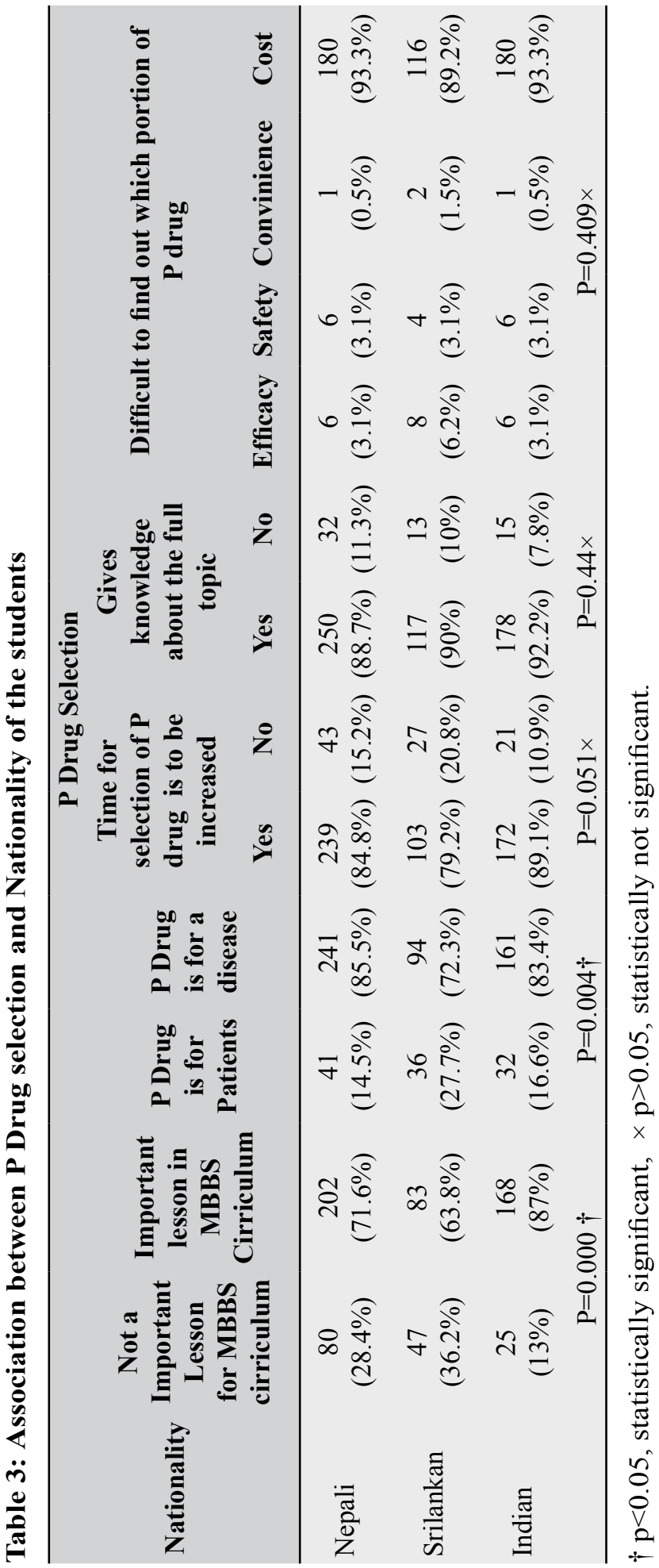

Determinants of $\mathbf{P}$ drug selection by logistic regression:

Male students considered that $\mathrm{P}$ dug selection as an important lesson for MBBS curriculum 2.037 times as compared to females [OR 2.037, 95\% (CI 1.404, 2.955)]. Male students [OR 1.838, 95\% (CI 1.173, 2.880)] opted for more time 1.838 times for selection of $\mathrm{P}$ drug as compared to females (Table 4).
Table 4: Logistic Regression table of P Drug Selection

\begin{tabular}{|c|c|c|}
\hline & $\begin{array}{l}\text { Important lesson in } \\
\text { MBBS Cirriculum }\end{array}$ & $\begin{array}{c}\text { Time for selection } \\
\text { of } P \text { drug is to be } \\
\text { increased }\end{array}$ \\
\hline Gender & $\begin{array}{c}\text { Odds Ratio } \\
\text { (Confidence Interval) }\end{array}$ & $\begin{array}{c}\text { Odds Ratio } \\
\text { (Confidence Interval) }\end{array}$ \\
\hline Female & 1 & 1 \\
\hline Male & $\begin{array}{c}2.037 \\
(1.404,2.955) \dagger\end{array}$ & $\begin{array}{c}1.838 \\
(1.173,2.880) \dagger\end{array}$ \\
\hline
\end{tabular}

$\dagger p<0.05$, statistically significant, $\times p>0.05$, statistically not significant.

\section{Discussion}

Around $3 / 4^{\text {th }}$ of the medical students felt $\mathrm{P}$ drug selection is an important part of MBBS curriculum. Similar findings were found by Banerjee et al in 2009. ${ }^{9}$ This is because P Drug selection is an exercise where a student learns the rationale drug usage for a particular disease objectively and in an unbiased manner. ${ }^{10}$

Most of the students felt That $\mathrm{P}$ drug selection gives knowledge of the full chapter on which $\mathrm{P}$ drug is being selected. This is because medical students during the exercise of selecting $\mathrm{P}$ drug for a particular disease should know about all the drugs related to that topic. They need to select the group of drugs based on the four criteria's of Efficacy, Safety, Cost, Convenience/suitability and student has to follow extensive steps of $\mathrm{P}$ drug selection. ${ }^{3,11}$

Most students responded as P Drug selection is for a disease whereas $18 \%$ thinks that it is for a patient. Similar findings were also found by Shankar PR which has shown that around $25 \%$ of the students were confused whether it is for doctor or the patient. ${ }^{12}$ This area needs to be addressed and with proper amendments in the teaching and learning methodology of $\mathrm{P}$ drug selection this misconception and confusion among the students can be reduced.

Time management was a problem faced by most of the students. Around $85 \%$ students felt that time should be increased. For giving scores on the efficacy Pharmacokinetics and Pharmacodynamics of the drugs has to be considered. For comparing the safety the adverse effects of the drugs, drug interactions has to be taken into the consideration

Around $90.1 \%$ of the students found it difficult to find out the cost of the drugs from different brands as compared with efficacy, safety and convenience. For comparing the Cost of drugs from different brands the total cost of the treatment should be calculated rather than the cost of per unit and the cheapest available brand is usually selected. For comparing the convenience availability of drugs, whether the drug is injection or oral medication, frequency of administration of a drug has to be considered. For getting 
information regarding the availability of the medicines in Nepal, Nepalese National Formulary is usually consulted by the students. ${ }^{13,14}$ Calculating the cost of all the drugs is a time taking process. Time for selection of $\mathrm{P}$ drug should be at least for 60 minutes for any disease so that a student doesn't feel time constrain and they can perform the exercise smoothly. Usually at MCOMS student use CIMS, Drug Today, Nepal Drug Review are used to calculate the cost. It could be due to the fact that the basic science medical is not exposed to the hospital and the pharmacy. This problem can be improved by periodic duty of the basic science medical students in the hospital and in the hospital pharmacy. ${ }^{12}$

\section{Conclusion}

The overall views of medical students on $\mathrm{P}$ drug selection were positive. The teaching and learning activity of P Drug Selection needs improvement in certain areas. In this exercise a student learns the rationale drug usage for a particular disease objectively and in an unbiased manner. With proper amendments in the teaching and learning methodology of $\mathrm{P}$ drug selection students can think and make decisions about the prescription writing which can reduce the chances of irrational prescribing by the future doctors.

\section{Recommendations}

Exercise of P Drug selection is carried out at basic science students who are studying pharmacology. P Drug selection can be implemented in the clinical side students who are studying Medicine, which can help the student to promote the rationale usage of medicine with the support of the clinicians. Interns can be also be benefited with this exercise by choosing the rationale drug for a particular disease objectively and in an unbiased manner.

\section{List of abbreviations}

MCOMS- Manipal College of Medical Sciences, IOMInstitute of Medicine, KISTMC- KIST Medical College

\section{Acknowledgments}

We prolong our deepest and warm gratitude to Late Dr Akhilesh Chandra Jauhari, Professor, Department of Pharmacology, Manipal College of Medical sciences, Nepal for all guidance, proposition and cooperation in writing this paper. We are grateful to Dr. B. M. Nagpal, Dean and CEO, MCOMS, Nepal. We are grateful to Dr. R.K.Sharma, Dean, Dr.D.Y.Patil Medical College, Mauritius for constant help and support.

\section{References}

1. Banerjee I, Jauhari AC, Bista D, Johorey A C, Roy B, Sathian B. Medical Students View about the Integrated MBBS Course: A Questionnaire Based Cross-sectional
Survey from a Medical College of Kathmandu Valley. Nepal Journal of Epidemiology 2011;1(3): 95-100.

2. Walley T, Bligh B (1993) The educational challenge of improving prescribing. Postgraduate Education for General Practice 4: 50-54.

3. De Vries TPGM, Henning RH, Hogerzeil HV, Fresle DF (1994) Guide to good prescribing. Geneva: World Health Organization.

4. Hogerzeil HV, Barnes KI, Henning RH, Kocabasoglu YE, Moller H, Smith AJ, Summers RS, de Vries TPGM (2001) Teachers' guide to good prescribing. Geneva: World Health Organization

5. Shankar PR, Gurung SB, Jha N, Bajracharya O, Ansari SR, Thapa HS. Practical assessment in Pharmacology at a new Nepalese medical school. J Clin Diagn Res 2010;4:3314-3316

6. Shankar PR. Seven years' experience of P-drug selection. AMJ.2011, 4, 4, 201-204.

7. Sathian B, Sreedharan J, Banerjee I, Roy B. Simple sample size calculator for medical research: a necessary tool for the researchers. Medical Science,2014:2(3)141-144.

8. WMA Declaration of Helsinki - Ethical Principles for Medical Research Involving Human Subjects.64th WMA General Assembly, Fortaleza, Brazil, October 2013. [online] 2013 [cited 2014 Dec 18]. Available from: http:/www.wma.net/en/30publications/10policies/b3/

9. Shankar PR . P-drug selection: Choosing medicines objectively. Nepal Journal of Epidemiology 2013;3 (2): 251

10. Banerjee I, Jauhari CA, Johorey CA, Gyawali S, Saha A. Student's Accreditation of integrated Medical Education in Nepal. Asian Journal of Medical Sciences 2011;2 (1): 49-52.

11. Banerjee I. Concepts of P-drug selection. Nepal Journal of Epidemiology 2013;3(1):226-229.

12. Shankar PR, Palaian S, Gyawali S, Mishra P, Mohan L.Personal drug selection: Problem based learning in Pharmacology: Experiences from a medical school in Nepal. PLoS One 2007; 2: e524. www.plosone.org/ article/info:doi/ 10.1371/journal.pone.0000524

13. Bhattarai DD, Shrestha DA, Dixit H, AcharyaLI, KafleKK, Prasad RR, Thapa BB. National List of Essential Drugs. Nepalese National Formulary. 1sted. Kathmandu:Kanchan Printing Press,1997,pp 353.

14. Kafle KK, Prasad RR, Thapa BB. National List of Essential Medicine (forth revision draft). Nepalese National Formulary. 2nd ed. Kathmandu, 2010, pp 195. 